SILVA, T.C. et al. Papel da fermentação lática na produção de silagem. PUBVET, Londrina, V. 5, N. 1, Ed. 148, Art. 998, 2011.

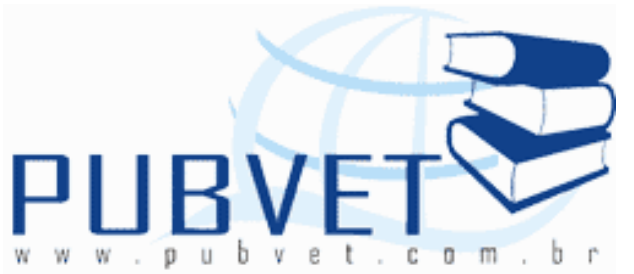

PUBVET, Publicações em Medicina Veterinária e Zootecnia.

\title{
Papel da fermentação lática na produção de silagem
}

Thiago Carvalho da Silva ${ }^{1}$, Marcus Vinicius Bastos da Silva², Eder Galinari

Ferreira ${ }^{2}$, Odilon Gomes Pereira ${ }^{3}$, Célia Lúcia de Luces Fortes Ferreira ${ }^{4}$

${ }^{1}$ Doutorando em Zootecnia - Universidade Federal de Viçosa (UFV), Viçosa/MG

${ }^{2}$ Mestrando em Ciência e Tecnologia de Alimentos - UFV, Viçosa/MG

${ }^{3}$ Professor Associado do Departamento de Zootecnia - UFV, Viçosa/MG

${ }^{4}$ Professor Titular do Departamento de Tecnologia de Alimentos - UFV, Viçosa/MG

\section{Resumo}

A ensilagem é o método de conservação da forragem sob condição de anaerobiose, onde ocorre uma metabiose, ou seja, uma sucessão de grupos de microrganismos até atingir um nível de acidez, por meio da produção de ácido lático pelas bactérias produtoras de ácido lático (BAL), no qual o desenvolvimento de microrganismos deterioradores,que são menos tolerantes às condições ácidas é inibido. Considera-se fermentação lática, aquela na qual o ácido lático é o principal produto final da fermentação. Portanto, bactérias homofermentativas, como Lactobacillus lactis, são desejáveis no processo de fermentação de silagens, uma vez que nesses microrganismos mais de $87 \%$ dos compostos do metabolismo é ácido lático. Já na heterofermentação produtos adicionais como etanol ou acetato são formados, bem como $\mathrm{CO}_{2}$. Inoculantes microbianos usados como aditivos incluem bactérias 
SILVA, T.C. et al. Papel da fermentação lática na produção de silagem. PUBVET, Londrina, V. 5, N. 1, Ed. 148, Art. 998, 2011.

homofermentativas, heterofermentativas, ou a combinação destas. Devido à especificidade existente entre a espécie forrageira e sua microflora epifítica, estudos visando isolar e identificar os principais grupos microbianos presentes nas principais plantas forrageiras utilizadas para ensilagem são necessários. Embora um grande número de trabalhos tem sido realizado para a produção de silagens, atualmente, não existe um padrão dessas respostas. Sabe-se que essas respostas dependem da forragem utilizada, da estirpe presente no inoculante e da sua concentração no momento da inoculação. Recomenda-se a realização de mais estudos avaliando-se o efeito dos inoculantes, principalmente sobre as perdas e sobre a sua viabilidade econômica, uma vez que a magnitude observada dessas respostas é baixa.

\section{Role of latic acid fermentation in silage production}

\section{Abstract}

Silage is the method of forage anaerobic conservation, where a metabiosis, or a succession of microbial groups containing lactic acid-producing bacteria (LAB), in which the development of spoilage microorganisms, which are less tolerant to acidic conditions, is inhibited. So homofermentative bacteria growing in the first stages of silage fermentation, such as Lactobacillus lactis, are desirable in the process of fermentation of silage. In the homofermentation, more than $87 \%$ of the latic acid is produced. In heterofermentation, additional products such as ethanol/acetate and $\mathrm{CO}_{2}$ are formed. Microbial inoculants used as additives include homofermentative, heterofermentative $L A B$, or both. Due to specificity between the forage species and their epiphytic microflora, studies aiming to isolating and identifying the main microbial groups present in the main forage plants used for silage are scarce. It is known that inocula response are forage dependent. Therefore it is recommended studies which emphasizes dry matter losses and their relations to economic viability. 
SILVA, T.C. et al. Papel da fermentação lática na produção de silagem. PUBVET, Londrina, V. 5, N. 1, Ed. 148, Art. 998, 2011.

\section{Introdução}

A ensilagem é uma alternativa muito empregada nos sistemas de criação animal. Consiste na preservação de forragens úmidas, recém-colhidas, com elevado valor nutritivo, para serem administradas nas épocas de escassez de alimentos. Consiste em um método de conservação da forragem sob condição de anaerobiose, onde ocorre uma metabiose, ou seja, uma sucessão de grupos de microrganismos até atingir um nível de acidez, pelo acúmulo de ácidos orgânicos, no qual o desenvolvimento de microrganismos deterioradores, que são menos tolerantes às condições ácidas é inibido. Dentre os grupos de microrganismos deterioradores destacam-se as enterobactérias e os clostrídios (WOOLFORD 1984; PEREIRA e SANTOS, 2006).

As bactérias ácido lático (BAL) da microflora epifítica (endógena) são essenciais para fermentação das silagens. Entretanto, esse grupo apresenta grande variação em concentração e espécie. Essa variação tem sido reportada do limite de detecção $10^{1}$ a $10^{5}$ UFC $\mathrm{g}^{-1}$ forragem na alfafa até $10^{6} \mathrm{em}$ gramíneas perenes e $10^{7}$ em milho e sorgo (PAHLOW et al., 2003). Populações dentro dessa faixa têm sido também registradas em condições tropicais, para diferentes espécies forrageiras (ROCHA, 2003; PEREIRA et al; 2005; PEREIRA et al., 2006; SOUSA et al., 2006).

$\mathrm{O}$ pH ideal para silagens de boa qualidade fica na faixa de 3,8 e 4,2 (Mc DONALD et al., 1991). Assim, quanto mais rápida for a queda do $\mathrm{pH}$, menores serão as perdas na ensilagem devido à maior conversão dos carboidratos solúveis da planta (principal substrato para as BAL) em ácido lático, com uma maior recuperação de energia em relação às outras fermentações, pois não há perda de carbono na forma de $\mathrm{CO}_{2}$ (Mc Donald et al., 1991). Características como o elevado teor de carboidratos solúveis, de matéria seca (MS) e baixo poder tampão são recomendadas para a espécie forrageira que se pretende conservar. O poder tampão reflete a capacidade de resistir a alterações no $\mathrm{pH}$, determinada por substâncias tamponantes, representadas nas plantas por bases inorgânicas de $\mathrm{K}$ e CA, proteína, nitrogênio amoniacal $\left(\mathrm{N}-\mathrm{NH}_{3}\right)$, sais orgânicos (malato, citrato, entre outros). 
SILVA, T.C. et al. Papel da fermentação lática na produção de silagem. PUBVET, Londrina, V. 5, N. 1, Ed. 148, Art. 998, 2011.

As BAL apresentam papel fundamental no processo de ensilagem, pois alem de inibir o crescimento de microrganismos deterioradores, possibilitam uma maior recuperação da energia dos carboidratos fermentados por meio da produção de ácido lático. A presença de bactérias ácido-láticas homofermentativas é necessária principalmente na fase inicial da fermentação. A geração de $\mathrm{CO}_{2}$ pelas bactérias heterofermentativas resulta em perda de carbono, ou seja, perda de nutrientes dos materiais das plantas. Portanto, BAL, como Lactobacillus plantarum, são desejáveis no processo de fermentação de silagens. BAL estão geralmente presentes em gramíneas e culturas anuais, todavia, há uma variação nas espécies e número de BAL de acordo com as diferentes plantas, solos e estações do ano (Ávila et al. 2009a). A maioria dos inoculantes é composta de bactérias homofermentativas. A eficiência de um inoculante depende da concentração do inóculo, bem como do teor de açúcar do material ensilado. Materiais com menos de $2 \%$ de açúcar, fermentados com inolulantes que contenham menos de $10^{5-6}$ UFC dificilmente resultarão em silagem de boa qualidade (OHMOMO et al. 2002).

Neste trabalho serão discutidos o processo de ensilagem, o papel das bactérias ácido lático e os seus efeitos sobre as características das silagens.

\section{O processo de ensilagem}

O processo de ensilagem tem como objetivo principal preservar os nutrientes presentes na forragem, com o mínimo de perdas de MS e energia (Souza et al., 2009). É dividido em quatro fases, de diferentes durações e intensidades, as quais não podem ser separadas precisamente uma da outra (PAHLOW et al., 2003):

Fase 1: Fase aeróbia inicial - Caracteriza-se pela presença de oxigênio junto ao material que será ensilado. Nesta, a principal reação que ocorre é a respiração celular, que utiliza o oxigênio do ar e substratos presentes no material picado, produzindo $\mathrm{CO}_{2}$, calor e $\mathrm{H}_{2} \mathrm{O}$. Os substratos usados para a respiração são os carboidratos solúveis (CS), devido à facilidade com que são assimilados ao processo. Eles são formados de açúcares simples e se prestam 
SILVA, T.C. et al. Papel da fermentação lática na produção de silagem. PUBVET, Londrina, V. 5, N. 1, Ed. 148, Art. 998, 2011.

tanto como substrato para o processo fermentativo da silagem como energia para o animal.

Assim, quanto mais tempo o material permanecer picado e exposto ao ar (O2), mais CS será consumido, podendo implicar em menor conteúdo energético da silagem, menor eficiência no processo de fermentação e aquecimento excessivo da massa ensilada. Mesmo depois de compactado e vedado, o material estará em contato com o $\mathrm{O}_{2}$. Esse $\mathrm{O}_{2}$ precisa ser consumido para que o meio se torne anaeróbico, e isso só é possível pela respiração celular. A quantidade de respiração que ocorrerá (e conseqüentemente consumo de $\mathrm{CS}$ ) dependerá da disponibilidade de $\mathrm{O} 2$ presente no material ensilado. Por essa razão, recomenda-se rapidez nos processos de colheita, picagem e descarregamento, aliados à eficiência (e também rapidez) na compactação e vedação final do silo. Com uma boa picagem, compactação e vedação, espera-se que em poucas horas se esgote todo o 02 presente na massa ensilada e o ambiente se torne anaeróbico.

Do ponto de vista fermentativo, a fase aeróbica é indesejável. No entanto, ela é fase obrigatória no processo de ensilagem, mas deve ser reduzida ao mínimo adotando algumas praticas de manejo anteriormente mencionadas.

Fase 2: Fase de fermentação principal - Esta fase se estende por uma a quatro semanas (Muck \& Pitt, 1993), dependendo das propriedades do material ensilado e das condições de ensilagem. Uma vez que as condições de anaerobiose são estabelecidas, os microrganismos anaeróbios dominam o processo de fermentação. O principal produto da fermentação é o ácido lático, que ajuda as BAL nos estádios iniciais da fermentação controlarem uma variedade de microrganismos anaeróbios facultativos e obrigatórios, tais como enterobactérias, leveduras, bacilos e clostrídios, que competem por carboidratos solúveis em água. O princípio da ação dos ácidos orgânicos é baseado nos diferentes níveis de resistência dos microrganismos à acidez. Ou seja, com o progresso da fermentação, a população de BAL aumenta, produzindo quantidades crescentes de ácido lático, dominando assim, a microflora remanescente na massa ensilada. Essa fase se prolonga até que o 
SILVA, T.C. et al. Papel da fermentação lática na produção de silagem. PUBVET, Londrina, V. 5, N. 1, Ed. 148, Art. 998, 2011.

$\mathrm{pH}$ seja reduzido o suficiente para inibir o crescimento das BAL, iniciando-se a fase de estabilização (OHMOMO et al., 2002).

Fase 3: Fase estável - Nesta fase, somente a hidrólise ácida de polissacarídeos e a proteólise são mantidas, como resultado da atividade de enzimas ácido-tolerantes (PAHLOW et al., 2003). No entanto, várias espécies de leveduras altamente ácido-tolerantes sobrevivem nesta fase em estádio inativo, juntamente com bacilos e clostrídios, que estão dormentes, na forma de endosporos. Neste período, podem ocorrer fermentações secundárias, resultando em deterioração da silagem. Estas fermentações estão associadas a deficiência de carboidratos fermentescíveis, ou a uma lenta produção de ácido lático, conduzindo a uma ineficiente inibição da flora deterioradora, como as bactérias do gênero Clostridium.

Fase 4: Fase de descarga - Nesta fase, após a abertura do silo, a silagem, que foi previamente mantida sob condições de anaerobiose, é exposta ao oxigênio. A presença de oxigênio favorece a atividade de microrganismos indesejáveis, tais como fungos, leveduras e bactérias ácido acético. Estes microrganismos utilizam substratos residuais e produtos da fermentação para seu crescimento, resultando em deterioração da silagem. Os principais indicadores desta deterioração são a produção de calor e $\mathrm{CO}_{2}$, devido à respiração, diminuição da concentração de ácido lático e aumento no pH, assim como decréscimo substancial no valor nutricional. Silagens que sofreram deterioração são denominadas de silagens instáveis anaerobiamente, nas quais as perdas de matéria seca podem ser elevadas. Segundo Oude Elferink et al. (2002), perdas de matéria seca da ordem de $1,5-4,5 \%$ dia ${ }^{-1}$ podem ocorrer, nas áreas afetadas.

\section{Fermentação lática}

Considera-se fermentação lática, aquela na qual o ácido lático é o principal produto final da fermentação. A flora de BAL é frequentemente dividida em dois tipos de fermentação de hexose a ácido lático. Na homofermentação o ácido lático é o principal produto do metabolismo. Na heterofermentação 
SILVA, T.C. et al. Papel da fermentação lática na produção de silagem. PUBVET, Londrina, V. 5, N. 1, Ed. 148, Art. 998, 2011.

produtos adicionais como etanol/acetato e $\mathrm{CO}_{2}$ são formados. Se pentoses tais como xilose ou arabinose são usadas como substratos, os produtos finais formados por ambos tipos fermentativos são idênticos, normalmente ácido lático e acético, sem produção de $\mathrm{CO}_{2}$ (Woolford, 1984).

Para as espécies do gênero Lactobacillus, três grupos foram definidos com base na presença ou ausência das enzimas aldolase e fosfocetolase (Kandler e Weiss, 1986).

Grupo 1: Homofermentativas obrigatórias, que fermentam hexoses homolaticamente, quase que exclusivamente a ácido lático ( $>85 \%)$, porém, são incapazes de fermentar pentoses, dada a falta da enzima fosfocetolase;

\section{Lactobacillus homofermentativos}

1A. Lactobacillus delbrueckii subsp. Delbrueckii

1B. Lactobacillus delbrueckii subsp. lactis

1C. Lactobacillus delbrueckii subsp. bulgaricus

2. L. acidophilus

3. L. amylophilus

4. L. amylovorus

5. L. animalis

6. L. crispatus

7. L. farciminis

8. L. gasseri

9. L. helveticus

10. L. jensenii

11. L. ruminis

12. L. salivarius

13. L. sharpeae

14. L. vitulinus

15. L. yamanashiensis

Grupo 2: Heterofermentaivas facultativas, que utilizam a mesma via das hexoses do grupo 1, porém são capazes de fermentar pentoses, pois possuem as enzimas aldolase e fosfocetolase;

Lactobacillus heterofermentativos facultativos (Kandler e Weiss, 1986)

16. L. agilis

17. L. alimentarius

18. L. bavaricus

19a. L. casei subsp. Casei

19b. L. casei subsp. pseudo-plantarum

19c. L. casei subsp. rhamnosus

19d. L. casei subsp. tolerans

20a. L. coryniformis subsp. coryniforms 20b. L. coryniformis subsp. Torquens

21. L. curvatus

22. L. homohiochii

23. L. maltaromicus

24. L. murinus

25. L. plantarum

26. L. sake 
SILVA, T.C. et al. Papel da fermentação lática na produção de silagem. PUBVET, Londrina, V. 5, N. 1, Ed. 148, Art. 998, 2011.

Grupo 3: Heterofermentativas obrigatórias, que fermentam hexoses, formando ácido láctico, etanol (ou ácido acético) e $\mathrm{CO}_{2}$, podendo ainda fermentar pentoses para formar ácido láctico e ácido acético.

\begin{tabular}{|l|l|}
\hline \multicolumn{2}{|c|}{ Lactobacillus heterofermentativos facultativos (Kandler e Weiss, 1986) } \\
\hline 27. L. bifermentans & 36. L. halotolerans \\
28. L. brevis & 37. L. hilgardii \\
29. L. buchneri & 38. L. kandleri \\
30. L. collinoides & 39. L. kefir \\
31. L. confusus & 40. L. minor \\
32. L. divergens & 41. L. reuteri \\
33. L. fermentum & 42. L. sanfrancisco \\
34. L. fructivorans & 43 L. Vaccinostercus \\
35. L. fructosus & 44 L. viridescens \\
\hline
\end{tabular}

\section{Bactérias ácido lático e seus efeitos na fermentação das silagens}

Os aditivos são classificados de acordo com as funções que exercem, ou seja, estimulantes da fermentação e inibidores da fermentação. Os estimulantes da fermentação podem ainda ser subdivididos em nutritivos (uréia, biureto, cama ou esterco puro de aves, melaço, carbonato de cálcio, concentrados e cana-de-açúcar), e não nutritivos (inoculantes bacterianos e enzimas, celulases e hemicelulases).

Inoculantes microbianos usados como aditivos incluem bactérias homofermentativas, heterofermentativas, ou a combinação destas. Os microrganismos homofermentativos caracterizam-se pela taxa de fermentação mais rápida, menor proteólise, maior concentração de ácido lático, menores teores de ácidos acético e butírico, menor teor de etanol, e maior recuperação de energia e matéria seca. Bactérias heterofermentativas utilizam ácido lático e glicose como substrato para produção de ácido acético e propiônico, os quais são efetivos no controle de fungos, sob baixo $\mathrm{pH}$. O uso de inoculantes microbianos e enzimo-microbianos têm sido amplamente documentado em 
SILVA, T.C. et al. Papel da fermentação lática na produção de silagem. PUBVET, Londrina, V. 5, N. 1, Ed. 148, Art. 998, 2011.

trabalhos de pesquisa (PENTEADO et al., 2007; ÁVILA et al., 2009a; ÁVILA et al., 2009b; JALČ et al., 2009; KUNG Jr, 2010; REICH \& KUNG Jr, 2010).

Zopollatto et al. (2009) num estudo de metanálise (1999-2009) detectaram uma limitação de dados sobre o efeito de aditivos microbianos na qualidade das silagens. Observaram que o número de trabalhos realizados é insuficiente para fornecer posições conclusivas sobre os efeitos dos aditivos, ressaltando ainda a escassez de dados em determinadas áreas, como o desempenho no gado leiteiro. Os resultados documentados por estes autores mostram que a magnitude das respostas, principalmente sobre o desempenho animal é baixa. Desta forma a justificativa para o uso desses aditivos deve ser avaliada considerando-se a diminuição das perdas na ensilagem e a maior preservação do valor nutritivo da planta. Além disso, constataram que a intensidade das respostas varia de acordo com a espécie vegetal e com o microrganismo estudado, sugerindo uma especificidade entre estes dois componentes.

No entanto, estudos realizados nas décadas de 80 e 90 já haviam mostrado que as respostas de fermentação diferem entre estirpes de uma mesma espécie (WOOLFORD E SAWCZYC 1984, HILL 1989; FITZSIMONS et al 1992). Hill (1989) observou que ao inocular na ensilagem de milho duas estirpes de Lactobacillus plantarum isoladas do milho e do capim, a estirpe dominante após a ensilagem foi a que havia sido isolada do milho. 0 mesmo foi observado para o capim, onde a população de batérias láticas foi dominada pelas suas estirpes.

Muitos dos resultados inconclusivos observados em estudos de fermentação de silagens podem estar relacionados a este princípio, que pode ter sido deixado de lado. Devido a essa especificidade existente entre a espécie forrageira e sua microflora epifítica, estudos visando isolar e identificar os principais grupos microbianos presentes nas principais plantas forrageiras utilizadas para ensilagem são necessários. Ávila et al (2009b) isolaram estirpes de L. buchneri em cana-de-açúcar (Saccharum officinarum L.) e verificaram que a adição de $L$. buchneri UFLA SIL 72 reduziu a população de fungos e a 
SILVA, T.C. et al. Papel da fermentação lática na produção de silagem. PUBVET, Londrina, V. 5, N. 1, Ed. 148, Art. 998, 2011.

concentração de etanol nas silagens. Santos et al. (2007) observaram redução na concentração de nitrogênio amoniacal e na população de enterobactérias em silagens de capim mombaça (Panicum maximum) inoculadas com isolados de L. plantarum provenientes da microflora epifítica.

Desta forma os inoculantes para silagem podem facilitar ou acelerar o processo de ensilagem, mas eles não substituem os fatores fundamentais (maturidade da planta, teor de matéria seca, a exclusão de oxigênio), que são primordiais para produção de silagem de boa qualidade. Dentre estes fatores a idade de rebrotação é a que influencia todas as características da silagem desde a fermentação até o valor nutritivo, considerando-se as perdas.

Meeske \& Basson (1998) avaliaram o efeito de inoculante contendo Lactobacillus acidophilus Lactobacillus delbruekii ssp. bulgaricus e Lactobacillus plantarum, sobre silagem de milho não verificaram efeito de inoculante sobre o $\mathrm{pH}$ e a produção de ácido lático em silagem de milho. Segundo os autores, a elevada concentração BAL presentes na planta antes da ensilagem (microflora epifítica), levaram a tais resultados. Além disso, a quantidade de bactérias do gênero Clostridium presentes em maior número no tratamento sem inoculantes, não resultou em diminuição do teor de proteína bruta da silagem não tratada, de modo que não foi detectada a formação de ácido butírico.

O elevado teor de carboidratos solúveis residuais das silagens, principalmente de milho, sorgo e cana-de-açúcar, favorece o processo de deterioração aeróbia por fungos e leveduras, ocasionando perdas após abertura dos silos. Contudo, os ácidos orgânicos produzidos pela fermentação das BAL heterofermentativas, principalmente o ácido acético apresenta ação fungicida e pode atenuar essa deterioração aumentando a estabilidade aeróbia das silagens (KUNG Jr. \& RANJIT, 2001; RANJIT \& KUNG Jr. 2000). Por isso, inoculantes contendo BAL heterofermentativas (ex. L. buchneri) têm sido utilizados visando aumentar a estabilidade aeróbia das silagens.

Ávila et al., (2009a) avaliaram a estabilidade aeróbia de silagens de capim mombaça Panicum maximum Jacq. cv. Mombaça) inoculadas com duas estirpes de Lactobacillus buchneri, uma proveniente de um inoculante 
SILVA, T.C. et al. Papel da fermentação lática na produção de silagem. PUBVET, Londrina, V. 5, N. 1, Ed. 148, Art. 998, 2011.

comercial e outra isolada de silagem de cana-de-açúcar (Saccharum spp.). Observou-se aumento nos teores de MS após a abertura dos silos, enquanto o teor de carboidratos solúveis não apresentou alteração, devido à baixa concentração residual, característica das silagens de capins. As concentrações de $\mathrm{NH}_{3}$ (\%N-total) observadas estavam acima dos $12 \%$ recomendados por Molina et al. (2002) para silagens de boa qualidade, indicando elevada proteólise durante a fermentação, devido ao baixo suprimento de carboidratos solúveis capaz de provocar o rápido abaixamento do $\mathrm{pH}$.

Kleinschimit e Kung Jr. (2006), em estudo de metanálise (43 experimentos), avaliaram o efeito de $L$ buchneri sobre a fermentação e estabilidade aeróbia de silagens de milho, gramíneas e grãos de pequeno porte. Em geral, a inoculação reduziu o $\mathrm{pH}$, as concentrações de ácido lático e contagem de fungos, e ao mesmo tempo aumentou as concentrações de ácido acético e a estabilidade aeróbia em todos os tipos de silagens. O aumento na estabilidade aeróbia foi mais pronunciado nas silagens de milho. Além disso, foi observado aumento nas concentrações de ácido propiônico e etanol e diminuição das concentrações de carboidratos solúveis nas silagens de gramíneas e grãos de pequeno porte. Observou-se correlação entre o aumento da concentração de ácido acético e a diminuição da população de fungos, ressaltando o seu efeito fungicida. Nos trabalhos avaliados a inoculação com $L$. buchneri modificou o perfil de fermentação das silagens, diminuindo a relação lactato:acetato, sem comprometer a eficência dos processos, pois os valores de recuperação de MS permaneceram acima de 90\%, valor preconizado como mínimo para essa variável nessas plantas. Os autores ainda sugerem a existência do efeito cultura-específico.

Avaliando silagens de cevada inoculadas com L. buchneri, Taylor et al. (2002) observaram diminuição do número de leveduras e mofos, aumento da estabilidade aeróbica sem alteração no consumo de MS e na produção de leite.

Na Tabela 1 encontram-se alguns trabalhos avaliando o efeito das BAL sobre a fermentação das silagens. Observa-se que não existe um padrão das respostas, como foi discutido anteriormente, e o seu efeito depende da cultura 
SILVA, T.C. et al. Papel da fermentação lática na produção de silagem. PUBVET, Londrina, V. 5, N. 1, Ed. 148, Art. 998, 2011.

utilizada, da estirpe do microrganismo e da sua concentração no momento da inoculação. Os efeitos, embora significativos, são de baixa magnitude, o que leva a refletir sobre o uso dos inoculantes sem o conhecimento dos princípios microbiológicos e das características da planta forrageira.

As BAL homofermentativas são utilizadas no intuito de melhorar o processo fermentativo da silagem por meio do aumento na concentração de ácido lático, o que diminui o nitrogênio amoniacal e as perdas de MS. Já as BAL heterofermentativas promovem melhorias principalmente após a abertura do silo, aumentando a estabilidade aeróbica da silagem, pela inibição do crescimento de fungos e leveduras. Assim, muitos dos trabalhos de pesquisa têm recomendado o uso de inoculantes combinando os dois grupos de BAL supracitados, devido à sua maior eficácia em relação ao uso isolado.

\section{Conclusões}

A fermentaçao lática é o ponto chave do qual depende todo o processo de ensilagem, devido à menor perda de nutrientes e preservação adequada do material ensilado.

O uso de bactérias láticas como aditivos para melhorar a qualidade das silagens deve levar em consideração a interação microrganismo-espécie forrageira, por que as estirpes apresentam efeito pronunciado nas espécies das quais já fazem parte da microflora epifítica.

Recomenda-se a realização de mais estudos avaliando o efeito dos inoculantes, principalmente sobre as perdas e sobre a sua viabilidade econômica, uma vez que a magnitude observada dessas respostas é baixa.

\section{REFERÊNCIAS BIBLIOGRÁFICAS}

ÁVILA, C.L.S.; PINTO, J.C.; FIGUEIREDO, H.C.P. et al. Estabilidade aeróbia de silagens de capim-mombaça tratadas com Lactobacillus buchneri. Revista Brasileira de Zootecnia, v.38, n.5, p.779-787, 2009a.

ÁVILA, C.L.S; PINTO, J.C.; FIGUEIREDO, H.C.P. et al. Effects of an indigenous and a commercial Lactobacillus buchneri strain on quality of sugarcane silage. Grass and Forage Science, v.64, n.4, p.384-394, 2009b. 
SILVA, T.C. et al. Papel da fermentação lática na produção de silagem. PUBVET, Londrina, V. 5, N. 1, Ed. 148, Art. 998, 2011.

FILYA, I; ASHBELL, G.; HEN, Y. et al. The effect of bacterial inoculants on the fermentation and aerobic stability of whole crop wheat silage. Animal Feed Science and Technology, v.88, p.39-46, 2000.

FILYA, I. The effect of Lactobacillus buchneri and Lactobacillus plantarum on the fermentation, aerobic stability, and ruminal degradability of low dry matter corn and sorghum silages. Journal of Dairy Science, v.86, p.3575-3581, 2003.

FITZSIMONS, A.; DUFFNER, F.; CURTIN, D. et al. Assessment of Pediococcus acidilactici as a potential silage inoculant. Appl. Environ. Microbiol. v.58, n.9, p.3047-3052, 1992.

HILL, H. A. Microbial ecology of lactobacilli in silage. In: Food for Thought - Proceedings of the 2nd Forage Symposium, Pioneer Hi-Bred International, Johnston, IA, pp. 47-64, 1989.

Jalč1, D.; Laukova, A.; Simonova, M. et al. The use of bacterial inoculants for grass silage: their effects on nutrient composition and fermentation parameters in grass silages. Czech Journal of Animal Science, v.54,n.2, p.84-91, 2009.

KANDLER, O.; WEISS, N. Lactobacillus. In: SNEATH, P. H. A.; MAIR, N. S.; SHARPE, M. E.; HOLT, J. G. Bergey's manual of systematic bacteriology. Baltimore: Williams and Wilkins, 1986.

KLEINSCHIMIT, D.H.; KUNG Jr., L. A meta-analysis of the effects of Lactobacillus buchneri on the fermentation and aerovic stability of corn and grass and small-grains silages. Journal of Dairy Science, v.89, n.10, p.4005-4013, 2006.

KUNG Jr., L.; RANJIT N.K. The effect of Lactobacillus buchneri and other additives on the fermentation and aerobic stability of barley silage. Journal of Dairy Science, v.84, n.5, p.1149-1155, 2001.

MAGALHÃES, V.J.A.; RODRIGUES, P.H.M. Avaliação de inoculante microbiano na composição bromatológica, fermentação e estabilidade aeróbia da silagem pré-seca de alfafa. Revista Brasileira de Zootecnia, v.33, n.1, p.51-59, 2004.

McDONALD, P.; HENDERSON, A.R.; HERON, S.J.E. The biochemistry of silage. $2^{a}$ ed. Mallow Chalcombe Publications, 1991. 340p.

MEESKE, R.; BASSON, H.M. The effect of a lactic acid bacterial inoculant on maize silage. Animal Feed Science Technology, v.70, n.3, p.239-247, 1998.

MOLINA, L.R.; GONÇALVES, L.C.; RODRIGUEZ, N.M. et al. Qualidade das silagens de seis genótipos de sorgo (Sorghum bicolor (L) Moench) em diferentes estádios de maturação. Arquivo Brasileiro de Medicina Veterinária e Zootecnia, v.54, n.2, p.159-168, 2002.

Muck, R.E. Silage Microbiology and Its Control through Additives. Revista Brasileira de Zootecnia, v.39, (supl. especial), p.183-191, 2010.

MUCK, R. E. Silage Inoculation: inoculation of silage and its effects on silage quality. In: Conference with Dairy and Forage Industries. Proceedings... Madison-US, p.43-51, 1996.

MUCK, R.E. PITT, R.E. The role of silage additives in making quality silage. In: SILAGE PRODUCTION FROM SEED TO ANIMAL. New York. Proceedings... New York: NRAS, n. 67, 1993. p. 57-66. 
SILVA, T.C. et al. Papel da fermentação lática na produção de silagem. PUBVET, Londrina, V. 5, N. 1, Ed. 148, Art. 998, 2011.

NKOSI, B.D.; MEESKE, R.; van der MERWE, H.J. et al. Effects of homofermentative and heterofermentative bacterial silage inoculants on potato hash silage fermentation and digestibility in rams. Animal Feed Science and Technology, v.157, p.195-200, 2010.

OHMOMO, S.; TANAKA, O.; KITAMOTO, H. K.; CAI, Y. Silage and microbial performance, old history but new problem. Japan Agricultural Research Quarterly (JARQ), v.36 n.2, p.5971, 2002.

OLIVEIRA, J.S.; SANTOS, E.M.; ZANINE, A.M. et al. Populações microbianas e composição química de silagem de capim-mombaça (Panicum maximum) inoculado com Streptococcus bovis isolado de rúmen. Archives of Veterinary Science, v.12, n.2. p.35-40, 2007.

PAHLOW, G; MUCK, R.E.; DRIEHUIS, F. et al. Microbiology of ensiling. In: BUXTON, D.R.; MUCK, R.E.; HARRISON, J.H. (Eds.) Silage science and technology. 1.ed. Madison: American Society of Agronomy, 2003. p.31-94.

PENTEADO, D.C.S.; SANTOS E.M.; CARVALHO, G.J.P. et al. Inoculação com Lactobacillus plantarum da microbiota em silagem de capim mombaça. Archivos de Zootecnia, v.56, n.214, p.191- 202, 2007.

PEREIRA, O. G. , SANTOS, E. M. Microbiologia e o processo de fermentação em silagens. In: PEREIRA, O. G., OBEID, J. A., NASCIMENTO JÚNIOR, D., FONSECA., D.M. (Eds..). III Simpósio sobre manejo estratégico da pastagem. Viçosa, 2006, p.393-430.

PEREIRA, O.G., SANTOS, E.M., FERREIRA, C.L.L.F. et al.. Populações microbianas em silagem de capim-mombaça de diferentes idades de rebrotação. In: XLIII Reunião Anual da Sociedade Brasileira de Zootecnia. João Pessoa-PB. Anais...UFPB. João Pessoa. 2006. CD-ROM.

PEREIRA, O.G.; SANTOS, E.M.; FERREIRA, C.L.L.F. et al. Populações microbianas em silagem de capim-mombaça de diferentes idades de rebrotação. In: XLIII REUNIÃO ANUAL DA SOCIEDADE BRASILEIRA DE ZOOTECNIA. João Pessoa. Anais... João Pessoa: UFPB, 2006. CDROM. Forragicultura.

RANJIT, N.K.; KUNG Jr., L. The Effect of Lactobacillus buchneri, Lactobacillus plantarum, or a Chemical Preservative on the Fermentation and Aerobic Stability of Corn Silage. Journal of dairy science, v. 83, n. 3, p. 526-535, 2000.

REICH, L.J.; KUNG Jr, L. Effects of combining Lactobacillus buchneri 40788 with various lactic acid bacteria on the fermentation and aerobic stability of corn silage. Animal Feed Science and Technology. v.159, p.105-109, 2010.

ROCHA, K.D. Silagens de capim-elefante cv. cameroon, de milho e de sorgo produzidas com inoculantes enzimo-bacterianos: populações microbianas, consumo e digestibilidade. Viçosa: Universidade Federal da Viçosa, 2003. 79p. Dissertação (Mestrado em Zootecnia) - Universidade Federal de Viçosa, 2003.

RODRIGUES, P.H.M.; ALMEIDA, T.F.; MELOTTI, L. et al. Efeitos da adição de inoculantes microbianos sobre a composição bromatológica e sobre a fermentação da silagem de girassol produzida em silos experimentais. Revista Brasileira de Zootecnia, v.30, n.6S p.216892175, 2001.

ROWGHANI, E.; ZAMIRI, M.J. The effects of a microbial inoculant and formic acid as silage additives on chemical composition, ruminal degradability and nutrient digestibility of corn silage in sheep. Iranian Journal of Veterinary Research, v.10, n.2, p.110-118, 2009. 
SILVA, T.C. et al. Papel da fermentação lática na produção de silagem. PUBVET, Londrina, V. 5, N. 1, Ed. 148, Art. 998, 2011.

SOUSA, L.O; SANTOS, E.M.; PENTEADO, D.C.S. et al. Composição bromatológica de silagem de capim-mombaça inoculada com lactobacilus plantarum da microbiota epifítica. IN: VI CONGRESSO NACIONAL DE ZOOTECNIA - ZOOTEC. Recife. Anais... Recife: UFRPE 2006. CDROM.

SOUZA, W.F.; RIGUEIRA, J.P.S.; ROSA, L.O. et al.Papel da fermentação propiônica na produção de silagem. PUBVET, Londrina, V. 3, N. 4, 2009. Disponível em: http://www.pubvet.com.br/artigos_det.asp?artigo=644. Acesso em: 04/12/2010.

TAYLOR, C. C.; RANJIT, N. J.; MILLS, J. A. et al. The effect of treating whole-plant barley with lactobacillus buchneri 40788 on silage fermentation, aerobic stability, and nutritive value for dairy cows. Journal of Dairy Science, v.85, n.7, p.1793-1800, 2002.

WEINBERG, Z.G.; ASHBELL, G.; HEN, Y. et al. Ensiling whole-crop wheat and corn in large containers with Lactobacillus plantarum and Lactobacillus buchneri. Journal of Industrial Microbiology \& Biotechnology, v.28, p.7-11, 2002.

WOOLFORD, M.K. \& SAWCZYC, M.K. An investigation into the effect of cultures of lactic acid bacteria on fermentation in silage. 1. Strain selection. Grass Forage Science. 39:139-148, 1984.

WOOLFORD, M.K. The silage fermentation. New York, Marcel Dekker, 1984. p.23-132.

ZANINE, A.M. et al. Avaliação da silagem de capim-elefante com adição de farelo de trigo. Archivos de Zootecnia, v.55, n.209, p.75-84, 2006.

ZHANG, T.; LI, L.; WANG, X. et al. Effects of Lactobacillus buchneri and Lactobacillus plantarum on fermentation, aerobic stability, bacteria diversity and ruminal degradability of alfalfa silage. World Journal of Microbiology and Biotechnology, v.25, p.965-971, 2009.

ZOPOLLATTO, M.; DANIEL, J.L.P.; NUSSIO, L.G. Aditivos microbiológicos em silagens no Brasil: revisão dos aspectos da ensilagem e do desempenho de animais. Revista Brasileira de Zootecnia, v.38, p.170-189, 2009 (supl. especial). 
SILVA, T.C. et al. Papel da fermentação lática na produção de silagem. PUBVET, Londrina, V. 5, N. 1, Ed. 148, Art. $998,2011$.

Tabela 1 - Efeito de inoculantes com bactérias láticas sobre o perfil fermentativo das silagens.

\begin{tabular}{|c|c|c|c|c|c|c|c|c|c|c|c|c|c|}
\hline Autor & ANO & Cultura & Microrganismo & $\mathrm{pH}$ & $\mathrm{NH}_{3}$ & $A L^{1}$ & $A A^{2}$ & $A P^{3}$ & $A B^{4}$ & $E T^{5}$ & $E A^{6}$ & $\mathrm{PMS}^{7}$ & $\mathrm{RMS}^{8}$ \\
\hline \multirow[t]{2}{*}{ Filya et al. } & 2000 & Trigo & $\begin{array}{l}\text { L. plantarum/ E. } \\
\text { faecium }\end{array}$ & -- & & ++ & ns & & ns & & ns & & \\
\hline & & & L. pentosus & -- & & ++ & ns & & ns & & ns & & \\
\hline \multirow[t]{3}{*}{ Rodrigues et al. } & 2001 & Girassol & $\begin{array}{l}\text { S. faecium/ P. } \\
\text { acidilacti/ } L . \\
\text { plantarum }\end{array}$ & ns & ns & ns & ns & ns & ns & & ns & ns & \\
\hline & & & $\begin{array}{l}\text { L. plantarum/ } \\
\text { Lactobacillus sp. }\end{array}$ & ns & ns & ns & ns & ns & ns & & ns & ns & \\
\hline & & & $\begin{array}{l}\text { S. faecium/ L. } \\
\text { plantarum }\end{array}$ & -- & -- & ns & -- & ++ & ns & & ns & ns & \\
\hline \multirow[t]{2}{*}{ Weinberg et al. } & 2002 & Trigo & L. buchneri & ns & & ns & ++ & & & & + & ++ & \\
\hline & & & L. plantarum & ns & & -- & ++ & & & & + & -- & \\
\hline \multirow[t]{3}{*}{ Filya } & 2003 & Trigo & L. buchneri & ++ & ns & -- & ++ & & & & ++ & ++ & \\
\hline & & & L. plantarum & ns & -- & ++ & ns & & & & ns & -- & \\
\hline & & & $\begin{array}{c}\text { L. plantarum/ L. } \\
\text { buchneri }\end{array}$ & ns & -- & ns & ++ & & & & ++ & -- & \\
\hline \multirow[t]{3}{*}{ Filya } & 2003 & Sorgo & L. buchneri & ns & ns & -- & ++ & & & & ++ & ++ & \\
\hline & & & L. plantarum & ns & -- & ns & ns & & & & -- & -- & \\
\hline & & & $\begin{array}{c}\text { L. plantarum/ L. } \\
\text { buchneri }\end{array}$ & ns & -- & -- & ++ & & & & ++ & -- & \\
\hline $\begin{array}{c}\text { Magalhaes \& } \\
\text { Rodrigues }\end{array}$ & 2004 & Alfafa & $\begin{array}{c}\text { L. plantarum/ } \\
\text { Pediococcus } \\
\text { pentosaceus }\end{array}$ & ns & ns & ns & ++ & ns & ns & ns & ns & & \\
\hline
\end{tabular}


SILVA, T.C. et al. Papel da fermentação lática na produção de silagem. PUBVET, Londrina, V. 5, N. 1, Ed. 148, Art. $998,2011$.

\begin{tabular}{|c|c|c|c|c|c|c|c|c|c|c|c|c|}
\hline \multirow[t]{2}{*}{$\begin{array}{c}\text { Kleinschimit \& } \\
\text { Kung Jr. }\end{array}$} & 2006 & Milho & L. buchneri & ++ & ns & - & ++ & ns & & ns & + & ns \\
\hline & & Capim & & -- & ns & -- & ++ & ++ & & ++ & + & -- \\
\hline \multirow[t]{2}{*}{ Jalc et al. } & 2009 & Capim & E. faecium & -- & ++ & ++ & -- & ns & & & & \\
\hline & & & L. plantarum & -- & -- & ++ & ++ & ns & & & & \\
\hline $\begin{array}{c}\text { Rowghani \& } \\
\text { Zamiri }\end{array}$ & 2009 & Milho & $\begin{array}{l}\text { P. acidipropionici/ } \\
\text { L.plantarum }\end{array}$ & -- & & -- & -- & -- & -- & & & ++ \\
\hline \multirow[t]{3}{*}{ Zhang } & 2009 & Alfafa & L. buchneri & -- & ns & ns & ++ & ns & -- & & ++ & \\
\hline & & & L. plantarum & -- & ns & ++ & ns & ns & -- & & ns & \\
\hline & & & $\begin{array}{l}\text { L. plantarum/ L. } \\
\text { buchneri }\end{array}$ & -- & -- & ++ & ++ & ns & -- & & ++ & \\
\hline Ávila & 2009 & $\begin{array}{l}\text { Cana-de- } \\
\text { acucar }\end{array}$ & L. buchneri & ns & & ns & ++ & ++ & ns & -- & + & \\
\hline \multirow[t]{2}{*}{ Nkosi et al. } & 2010 & $\begin{array}{l}\text { Batata + } \\
\text { FT* }\end{array}$ & L. buchneri & -- & -- & ++ & ++ & ns & -- & & ++ & \\
\hline & & & $\begin{array}{l}\text { L. paracasei/ L. } \\
\text { lactis/ P. acidilacti }\end{array}$ & -- & -- & ++ & -- & -- & -- & & -- & \\
\hline
\end{tabular}

*Co-produto da batata $+30 \%$ de farelo de trigo; ${ }^{*}$ ácido lático, ${ }^{2}$ ácido acético, ácido propiônico, ${ }^{3}$ ácido butírico, ${ }^{5}$ etanol, ${ }^{6}$ estabilidade aeróbica, ${ }^{7}$ perdas de matéria seca, ${ }^{8}$ recuperação de matéria seca.

ns = não significativo; $+=$ aumento numérico; - = diminuição numérica; $++=$ aumento significativo $(P<0,05) /$ -

- = diminuição significativa $(P<0,05)$. 